2 Simonneau G, Robbins I, Beghetti M, et al. Updated clinical classification of pulmonary hypertension. J Am Coll Cardiol 2009; 54: Suppl. S, S43-S54.

3 Tamby M, Chanseaud Y, Humbert M, et al. Anti-endothelial cell antibodies in idiopathic and systemic sclerosis associated pulmonary arterial hypertension. Thorax 2005; 60: 765-772.

4 Belizna C, Duijvestijn A, Hamidou M, et al. Antiendothelial cell antibodies in vasculitis and connective tissue disease. Ann Rheum Dis 2006; 65: 1545-1550.

5 Humbert M, Montani D, Perros F, et al. Endothelial cell dysfunction and cross talk between endothelium and smooth muscle cells in pulmonary arterial hypertension. Vasc Pharmacol 2008; 49: 113-118.

6 Hesselstrand R, Ekman R, Eskilsson J. Screening for pulmonary hypertension in systemic sclerosis: the longitudinal development of tricuspid gradient in 227 consecutive patients, 1992-2001. Rheumatology 2005; 44: 366.
7 Bordron A, Dueymes M, Levy Y, et al. The binding of some human antiendothelial cell antibodies induces endothelial cell apoptosis. J Clin Invest 1998; 101: 2029-2035.

8 Mihai C, Cohen Tervaert JW. Anti-endothelial cell antibodies in systemic sclerosis. Ann Rheum Dis 2010; 69: 319-324.

9 Witte T, Hartung K, Sachse C, et al. IgM anti-dsDNA antibodies in systemic lupus erythematosus: negative association with nephritis. Rheumatol Int 1998; 18: 85-91.

10 van Paassen P, Duijvestijn A, Debrus-Palmans L, et al. Induction of endothelial cell apoptosis by IgG antibodies from SLE patients with nephropathy: A potential role for anti-endothelial cell antibodies. Ann NY Acad Sci 2007; 1108: 147-156.

\title{
Levels of soluble human leukocyte antigen-G are increased in asthmatic airways
}

\section{To the Editors:}

Human leukocyte antigen-G (HLA-G) is a non-classical, class $\mathrm{Ib}$, major histocompatibility complex antigen, encoded by a gene on chromosome 6p21 within the HLA complex [1]. HLA-G is constitutively expressed during pregnancy where it has a critical role in maintaining immune tolerance toward the allogenic fetus and placenta $[2,3]$, but has also been associated with inflammatory diseases such as psoriasis, multiple sclerosis, and ulcerative colitis, and with solid-organ transplantation [3, 4]. We recently reported associations between variation in HLA-G and risk for asthma in Chicago-area asthma families, in multigenerational Dutch asthma families and in a birth cohort at high risk for developing asthma [1, 5]. A role for HLA-G in asthma pathogenesis was further suggested by the demonstration of expression of a soluble isoform of HLA-G, sHLA-G5, in airway epithelial cells [1] and of increased circulating plasma levels of sHLA-G in children with atopic asthma [6]. Because airway inflammation in asthma involves a T-helper cell (Th) type 2-skewing of lymphocytes similar to pregnancy, HLA-G is an attractive candidate molecule for promoting the immune profile characteristic of asthma. Localisation of HLA-G to airway epithelium suggests that its dysregulation could contribute to airway inflammation in chronic asthma. To evaluate this further, we hypothesised that HLA-G abundance would be increased in asthmatic airways.

To test this hypothesis, we measured concentrations of sHLA-G in bronchoalveolar lavage (BAL) fluid obtained from 12 non-asthmatic control subjects and 15 subjects with mild persistent asthma. The use of human subjects was approved by the University of Chicago Institutional Review Board (Chicago, IL, USA). Asthma was diagnosed using National Asthma Education and Prevention Program guidelines. Subjects with a smoking history of $\geqslant 10$ pack $\cdot \mathrm{yrs}^{-1}$, who had used oral corticosteroids within 6 months of study, who had received emergent care or had been hospitalised for asthma within 6 months of study, were excluded. Bronchoscopy was done at a time of stability for each subject.

The demographic, clinical and pulmonary function data for the subjects in our study are presented in table 1. As expected, subjects with asthma had a lower forced expiratory volume in $1 \mathrm{~s} \%$ predicted $(p=0.01)$, more atopy $(p=0.0001)$ and more peripheral blood eosinophils $(p=0.02)$ compared with control subjects. However, there were no significant differences in cells counts in bronchoalveolar lavage (BAL) fluid between the two groups. Lavage fluid was concentrated approximately 30-fold using Centriprep ultra-filtration chambers (Millipore, Inc., Billerica, MA, USA) with a 3-kD molecular weight cut-off filter. The retentate was analysed for the presence of sHLA-G using an ELISA assay (Exbio, Inc., Vestec, Czech Republic). The capture antibody, MEM-G/9, recognises shed G1 and secreted G5, and the secondary antibody, anti- $\beta 2 \mathrm{~m}$, ensures measurement of $\beta 2 \mathrm{~m}$-configured soluble G [7]. The limit of sensitivity was $\sim 0.2 \mathrm{U} \cdot \mathrm{mL}^{-1}$. Values were adjusted for the degree of concentration as noted above and expressed as $\mathrm{U} \cdot \mathrm{mL}^{-1} \mathrm{BAL}$ fluid.

sHLA-G levels were increased in the BAL fluid of 15 asthmatic subjects (median 6.8 (interquartile range, 2.8-7.8) $\mathrm{U} \cdot \mathrm{mL}^{-1}$ ) compared with 12 control subjects (median 1.6 (1.0 3.0) $\mathrm{U} \cdot \mathrm{mL}^{-1}, \mathrm{p}=0.01$ by Mann-Whitney test) (fig. 1). One control value and no asthmatic values were below the limit of detection for the assay. We also examined whether racial background accounted for the observed differences in sHLA-G. There was no significant difference in sHLA-G levels in nine Caucasian asthmatic subjects (median 5.6 (1.56.9) $\mathrm{U} \cdot \mathrm{mL}^{-1}$ ) versus six African-American asthmatic subjects (median $6.9(6.2,8.6) \mathrm{U} \cdot \mathrm{mL}^{-1}, \mathrm{p}=0.24$ by Mann-Whitney test). There were too few African-American control subjects for analysis in that group. 
TABLE 1 Demographic and clinical characteristics of study subjects

\begin{tabular}{|c|c|c|c|}
\hline & Normal & Asthmatic & p-value ${ }^{\#}$ \\
\hline Subjects $n$ & 12 & 15 & \\
\hline Female & $6(50)$ & $11(73)$ & 0.26 \\
\hline White & $11(92)$ & $9(60)$ & 0.09 \\
\hline Smoking history & $1(8)$ & $7(47)$ & 0.05 \\
\hline Past history of oral corticosteroid use & & $5(33)$ & \\
\hline Past hospitalisation for asthma & & $8(53)$ & \\
\hline Past history of emergent care for asthma & & $10(67)$ & \\
\hline Presence of $\geqslant 1$ positive skin prick tests to allergen & $1(8)$ & $14(93)$ & 0.0001 \\
\hline Peripheral blood eosinophil count cells $\mu \mathrm{L}^{-1}$ & $119 \pm 24$ & $218 \pm 29$ & 0.02 \\
\hline Methacholine PD20 $\mathrm{mg} \cdot \mathrm{mL}^{-1}$ & $>10^{\circ}$ & $1.35 \pm 0.47$ & \\
\hline
\end{tabular}

Data are presented as mean \pm SEM or $n(\%)$, unless otherwise stated. FVC: forced vital capacity; FEV1: forced expiratory volume in 1 s; pred: predicted; PD20: provactive

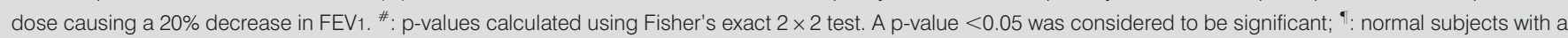
methacholine PD20 $<10 \mathrm{mg} \cdot \mathrm{mL}^{-1}$ were excluded from the study

Immunoperoxidase labelling of endobronchial biopsies fixed in $10 \%$ neutral buffered formalin was done using a primary antibody directed against sHLA-G (clone 2A12; Exbio, Inc.), which targets intron 4 sequences present only in sHLA-G. sHLA-G was present in the epithelium of endobronchial biopsies collected from 6 of 9 control subjects and 9 of 11 subjects with mild asthma that had sufficient epithelium present in the mucosal layer for review. Staining was evident in each major epithelial cell type (data not shown). No visible differences in labelling patterns or intensity were apparent

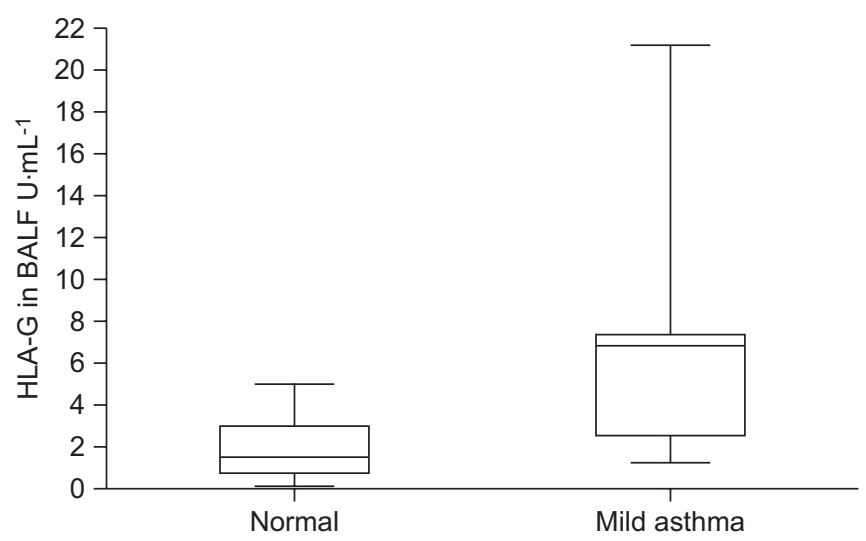

FIGURE 1. Level of soluble human leukocyte antigen (HLA)-G in bronchoalveolar lavage fluid (BALF) of 12 control subjects and 15 subjects with mild, persistent asthma. BALF was concentrated and then analysed by ELISA. Data are presented as a box plot showing the 25th (lower box) and 75th (upper box) percentiles; the bars demonstrate the range. The middle bar represents the median concentration. One control subject had a value below the limit of detection of the assay. between asthmatic and control subjects, and no other submucosal airway cells and structures were stained. No notable infiltration of inflammatory cells was present in any biopsy as judged by haematoxylin and eosin staining.

We report, for the first time, increased levels of sHLA-G in BAL fluid from subjects with asthma compared with control subjects, supporting a role for sHLA-G in asthma pathogenesis. Our results are consistent with our previous reports of associations between regulatory polymorphisms in HLA-G and asthma [1,5], and a study showing higher plasma levels of sHLA-G in 27 Turkish school children with atopic asthma compared with either 26 non-atopic, asthmatic children or 16 normal controls [6]. We note that all but one of our subjects with asthma was atopic and that we previously reported an association between HLA-G genotype and atopy in Dutch children [1]. Thus, it is possible that HLA-G influences asthma susceptibility through atopic pathways.

The source of the differences in HLA-G concentrations that we observed is the airway epithelium, as there was no detectable HLA-G in other airway structures. We propose that epithelialderived sHLA-G has a paracrine role in regulating the activity of key inflammatory cells found in asthmatic airways. We note that in other contexts HLA-G has been shown to suppress dendritic cells and T-cells that participate in inflammation [8], and to activate FoxP3+CD4+CD25+ regulatory T-cells that can suppress cells that participate in airway inflammation [9].

Our observation does not provide insights into cause and effect: is HLA-G driving the inflammation in asthmatic airways or is it a reactive attempt to suppress inflammation present in asthmatic airways? In pregnancy, HLA-G is thought to promote the skewing of T-cells toward a Th2 phenotype and to activate T-regulatory cells [2,3], an immune phenotype which parallels 
that seen in asthma. It is tempting to speculate that some individuals are genetically predisposed to over-express HLA-G in response to specific signals. Once secreted, HLA-G could promote a cascade of events that result in worsening inflammation. Several polymorphisms in the promoter region of $H L A-G$ coincide with transcription factor binding sites could account for inter-individual differences in expression of HLA-G [10]. We previously identified a polymorphism in the $3^{\prime}$ untranslated region of $H L A-G$ which disrupts a microRNA target site and demonstrated allele-specific expression of HLA-G in the presence of microRNAs that bind to that target [5]. Therefore, either lack of suppression or over-expression of HLA-G could explain the association we report here with asthma. We note that the small numbers of subjects in this study precludes more detailed analysis of relationships between genetic variation and HLA-G expression. Futuremore, larger studies are required to clarify the potential modulating role of HLA-G on the clinical manifestations of asthma and the role of genetic variation on expression levels.

In conclusion, sHLA-G is present in greater concentrations in BAL in mild asthma. We suggest that the overexpression or lack of suppression of HLA-G contributes to the disease process and that sHLA-G represents a novel pathway of asthma pathogenesis.

S.R. White*, D.A. Loisel ${ }^{\#}$, J.F. McConville*, R. Stern*, Y. Tu*, B.A. Marroquin*, I. Noth* and C. Ober ${ }^{*}$

Depts of ${ }^{*}$ Medicine, and ${ }^{*}$ Human Genetics, University of Chicago, Chicago, IL, USA.

Correspondence: S.R. White, University of Chicago, Section of Pulmonary and Critical Care Medicine, 5841 S. Maryland Ave., MC 6076, Chicago, IL 60637, USA. E-mail: swhite@medicine. bsd.uchicago.edu

Support Statement: This work was supported by AI056352, HL072414, HL080417, HL007605, HL095268 and RR024999 from the National Institutes of Health, Bethesda, MD, USA.
Acknowledgements: An abstract of a preliminary version of this manuscript was presented at the 2009 International meeting of the American Thoracic Society (San Diego, CA, USA) on May 19, 2009. The authors would like to thank S. Maleckar, and E. Low (University of Chicago, Chicago, IL, USA) for patient recruitment and technical assistance. They also thank J. Krishnan for advice on statistics; and J. Imperiale, the staff in the University of Chicago General Clinical Research Center and the pulmonary and critical care fellows at the University of Chicago (all University of Chicago, Chicago, IL, USA) for assistance with bronchoscopy.

\section{REFERENCES}

1 Nicolae D, Cox NJ, Lester LA, et al. Fine mapping and positional candidate studies identify HLA-G as an asthma susceptibility gene on chromosome 6p21. Am J Hum Genet 2005; 76: 349-357.

2 Hunt JS, Petroff MG, McIntire RH, et al. HLA-G and immune tolerance in pregnancy. FASEB J 2005; 19: 681-693.

3 Rouas-Freiss N, Naji A, Durrbach A, et al. Tolerogenic functions of human leukocyte antigen G: from pregnancy to organ and cell transplantation. Transplantation 2007; 84: Suppl. 1, S21-S25.

4 Carosella ED, Moreau P, Lemaoult J, et al. HLA-G: from biology to clinical benefits. Trends Immunol 2008; 29: 125-132.

5 Tan Z, Randall G, Fan J, et al. Allele-specific targeting of microRNAs to HLA-G and risk of asthma. Am J Hum Genet 2007; 81: 829-834.

6 Tahan F, Patiroglu T. Plasma soluble human leukocyte antigen G levels in asthmatic children. Int Arch Allergy Immunol 2006; 141: 213-216.

7 Fournel S, Huc X, Aguerre-Girr M, et al. Comparative reactivity of different HLA-G monoclonal antibodies to soluble HLA-G molecules. Tissue Antigens 2000; 55: 510-518.

8 Naji A, Le Rond S, Durrbach A, et al. CD3+CD4low and CD3+CD8low are induced by HLA-G: novel human peripheral blood suppressor T-cell subsets involved in transplant acceptance. Blood 2007; 110: 3936-3948.

9 Lee JH, Yu HH, Wang LC, et al. The levels of CD4+CD25+ regulatory $\mathrm{T}$ cells in paediatric patients with allergic rhinitis and bronchial asthma. Clin Exp Immunol 2007; 148: 53-63.

10 Tan Z, Shon AM, Ober C. Evidence of balancing selection at the HLA-G promoter region. Hum Mol Genet 2005; 14: 3619-3628.

\section{Pneumocystis pneumonia in an HIV-negative patient with no overt risk factors on presentation}

\section{To the Editors:}

Pneumocystis pneumonia (PCP) is a potentially life-threatening opportunistic infection that can occur in HIV-positive and HIV-negative individuals. The most significant risk factor for PCP in HIV-negative patients is chemotherapy, with a median time from cancer diagnosis to the first episode of PCP of 2 yrs. We report here a case of PCP in an adult male who had no identifiable risk factors on presentation. 3 weeks after the first signs and symptoms of PCP, he manifested blast crisis of acute myeloid leukaemia. This would be the first case demonstrating PCP as the sole presentation of an underlying occult leukaemia.

Our patient was a 55-yr-old homosexual male nonsmoker who presented with a 7-day history of progressive dyspnoea, dry cough, fever and chills. On examination, the patient's blood pressure was $130 / 70 \mathrm{mmHg}$, heart rate was 95 beats $\cdot \mathrm{min}^{-1}$, respiratory rate 25 breaths $\cdot \mathrm{min}^{-1}$, oxygen saturation $95 \%$ (3 L nasal oxygen), and temperature $37.9^{\circ} \mathrm{C}\left(100.2^{\circ} \mathrm{F}\right)$. The remainder 